\title{
Machine Sensibility
}

\author{
Unpacking the Embodied and Situated Dimensions of 3D Printing
}

\author{
SOPHIE LANDWEHR SYDOW \\ School of Natural Sciences, \\ Technology and Environmental \\ Studies, Södertörn University, \\ Huddinge, Sweden \& Department of \\ Computer and System Sciences, \\ Stockholm University, Sweden \\ sophie.landwehrsydow@sh.se
}

\author{
MARTIN JONSSON \\ School of Natural Sciences, \\ Technology and Environmental \\ Studies, Södertörn University, \\ Huddinge \\ martin.jonsson@sh.se
}

\author{
JAKOB THOLANDER \\ Department of Computer and System \\ Sciences, Stockholm University, \\ Stockholm, Sweden \\ jakobth@dsv.su.se
}

\begin{abstract}
This paper offers a conceptual contribution to understand 3D printing practice. We have studied conversations between 3D printing practitioners who discuss failed and discarded printed artifacts and analyzed how they make sense of the printing process. Based on findings of interactions with the machine itself, materials used, and designs applied, this study contributes to the field of HCI by highlighting the embodied and situated dimensions of 3D printing. Introducing the concept of machine sensibility, we characterize our findings around: i) assessing printability, ii) monitoring and intervening and iii) reading the prints. We use the term machine to highlight the importance of understanding the materiality of the $3 \mathrm{D}$ printer, and sensibility, to address critical interactions and abilities that surfaced in studying this practice. The concept allows researchers to put 3D printing practice in the context of contemporary interaction design research and helps to understand challenges of material-machine-design interdependencies.
\end{abstract}

\section{CCS CONCEPTS}

- Human-centered computing $\rightarrow$ Human computer interaction (HCI); HCI theory, concepts and models; Interaction design; Empirical studies in interaction design.

\section{KEYWORDS}

3D printing, machine sensibility, personal fabrication, embodied interaction, 3D printing practice, failure, material turn, human machine interaction

\section{ACM Reference Format:}

SOPHIE LANDWEHR SYDOW, MARTIN JONSSON, and JAKOB THOLANDER. 2020. Machine Sensibility: Unpacking the Embodied and Situated Dimensions of 3D Printing. In Proceedings of the 11th Nordic Conference on Human-Computer Interaction: Shaping Experiences, Shaping Society (NordiCHI '20), October 25-29, 2020, Tallinn, Estonia. ACM, New York, NY, USA, 13 pages. https://doi.org/10.1145/3419249.3420166

Permission to make digital or hard copies of all or part of this work for personal or classroom use is granted without fee provided that copies are not made or distributed for profit or commercial advantage and that copies bear this notice and the full citation on the first page. Copyrights for components of this work owned by others than ACM must be honored. Abstracting with credit is permitted. To copy otherwise, or republish, to post on servers or to redistribute to lists, requires prior specific permission and/or a fee. Request permissions from permissions@acm.org.

NordiCHI '20, October 25-29, 2020, Tallinn, Estonia

(C) 2020 Association for Computing Machinery.

ACM ISBN 978-1-4503-7579-5/20/10 . \$15.00

https://doi.org/10.1145/3419249.3420166

\section{INTRODUCTION}

In this paper, we present results from a study of practitioners' conversations and reflections on common struggles with the materials of desktop 3D printing machines. We introduce and characterize the concept of machine sensibility to point to how practitioners make sense of the 3D printer, its inner workings, their awareness of the contingencies of the machine, and how practitioners make judgments by drawing on tactile examinations and personal experience. By bringing the character of the $3 \mathrm{D}$ printer as a machine into focus, we highlight the embodied and situated subtleties of interacting with them.

Personal fabrication technologies and - most notably - 3D printers have emerged as increasingly influential in Human-computer interaction (HCI), interaction design and related fields [1, 3, 21, 30, $34,35,45]$. Like traditional printers they bridge the realms of the digital and the physical by transforming digital designs into physical artifacts. While traditional printing results in a representation of text or graphics on paper, 3D printers make use of filament to build a three-dimensional artifact layer by layer. Hence, "by providing a tighter coupling and faster iteration between the digital and physical, fabrication enables new relationships between objects and interfaces" [33]. This has led to novel designs of customized objects, experimental material choices, which have been changing the way how people design, produce and interact with objects and devices [17].

When addressing $3 \mathrm{D}$ printing in this paper, we specifically refer to practices using smaller desktop machines that use Fused Deposition Modeling (FDM) technology as its additive manufacturing process. These types of consumer oriented products have recurrently come with promises of easy and accessible ways to manufacture prototypes, toys and objects for everyday home use $[17,29,52]$. However, Williams and Nadau argue: "While manufacturing hardware may be much easier than it used to be, that does not make it, in any absolute sense, easy" [61]. As these types of 3D printers already inhabit makerspaces, design agencies, school labs, libraries and homes of technology enthusiasts [19, 50, 52, 54], they have become part of the ecosystem of interactive devices that people may encounter in their everyday lives. Several scholars in HCI have studied the challenges that 3D printing practitioners face, such as Ludwig et al. who mapped out design implications when making use of and appropriating desktop 3D printers [32] and proposing new infrastructures for embedding social support [30]. Others have 


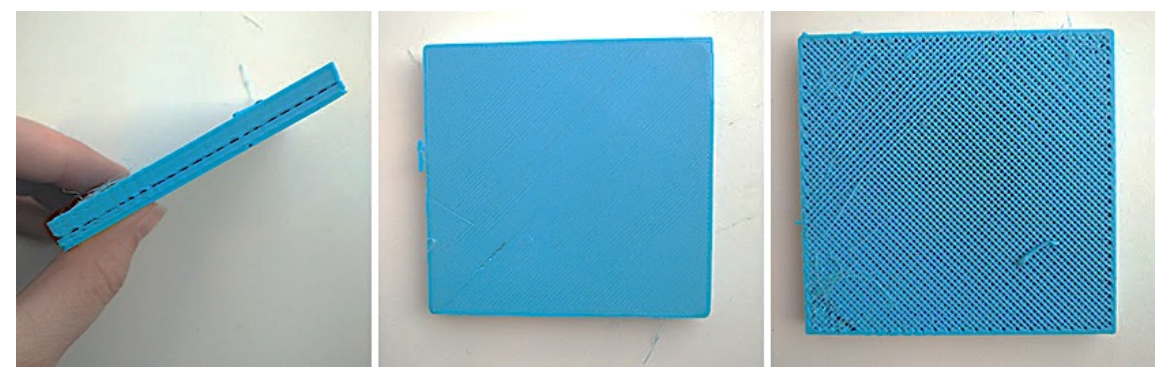

Figure 1: A failed print from the side, the bottom and the top.

examined the approaches of newcomers to 3D printing and identified barriers in expertise [23, 24], explored potential motivations for its use in home settings [52] and discuss technological challenges for making $3 \mathrm{D}$ printers more accessible and easier to use $[3,15,38]$.

We contribute to the discourse on 3D printing practice in $\mathrm{HCI}$ by offering a qualitative approach that links to prominent strands of $\mathrm{HCI}$ from the past and emphasize the practitioners situated and embodied interactions. We ask how these practices are significantly affected by the properties of the 3D printer as a machine, including its physicality and partially autonomous function. Our contributions are based on an analysis of data collected at a workshop with 3D printing practitioners, which followed a two-year ethnographic involvement at a community-driven makerspace. In this earlier ethnographic observation at the makerspace, the 3D printer became particularly interesting as it combines the design of digital and physical artifacts, common to maker practice. In a subsequent workshop, we asked nine practitioners with varied experience and expertise in 3D printing to explore a selection of discarded - or failed 3D - printed artifacts, previously gathered in the observed makerspace. Using other makers' failed prints as tactile tokens, we gathered notions on failures in the design, workings of the machine and behavior of the materials, as interpreted by the workshop participants. As typical example is P3's reflection on the artifact shown in figure 1

"I thought that it's tragic - I loved that it looked perfect, almost, but that it's broken on the inside. . you know that it was under-extruded in there for a while... and that it seems that it has gone back on track".

The remainder of this paper is based on an exploration of how practitioners' describe the fabrication processes of 'making' with a 3D printer, based on the traces they identified in discarded prints of this kind. The data collected at the workshop serves as a vehicle to make way to our analytical work on practitioners' situated and embodied interactions around 3D printers. Drawing on our findings, we argue that there is a need to revisit how HCI understands and conceptualizes certain machines and their role in interaction design. Along these lines, we introduce the notion of machine sensibility as a way to understand certain aspects involved in 3D printing practice, which emerged from three themes discovered in our findings: i) assessing printability, ii) monitoring and intervening and iii) reading the prints. In summary, the concept of machine sensibility aims to point at some of the subtle situated and embodied actions that are part of interacting with a machine. It can assist practitioners to describe the making process they engage in and provide researchers with a vocabulary to study and refer to this type of practice. In the discussion, we reflect on how machine sensibility can be used as an analytic lens to further consider design oriented interactions in digital fabrication. We use the concept of 'machine' by drawing on some historic and current strands of $\mathrm{HCI}$ research and explore how machines can be understood in relation to contemporary discourses on personal fabrication.

\section{RELATED WORK}

Modern machines are described as complex systems consisting of a multitude of mechanisms, structural elements and control components, often including digital interfaces for convenient use. When talking about machines in HCI today, it can refer to a multitude of things: it can relate to personal computers, smartphones and wearables, as well as to robots, ambient devices or assistive technology. It may include artificial intelligences, machines that learn or as in our case - machines that fabricate. In this paper, we use the term machine to highlight the importance of understanding the materiality of the 3D printer as a machine.

An overarching observation in our study is that through the appearance of the desktop 3D printer and other fabrication technology, the machine - understood as the noisy, smelly apparatus that we normally associate with the industrial revolution - has reappeared in the context of $\mathrm{HCI}$ and interaction design. The conversations that we collected resemble some of the early studies of personal computers and photocopiers from the 1980's. The interdisciplinary work conducted at Xerox PARC and the studies of photocopiers and expert systems initiated a perspective on human machine interaction that put situated and improvised action at the core. Lucy Suchman [55] and Julian Orr [39] among others provided insight into the practices and struggles surrounding these machines, both regarding use and work. Among other things, their arguments emphasised that the fundamental challenges in human interactions with machines cannot be solved by technological development only. In Duguid's words: "Those who complained that machines failed to live up to expectation could simply be told 'they will improve' and Moore's Law suggested how" [12]. We argue that this is where practice and promise differ. While technical development will overcome certain technical limitations and flaws in design, studies of the practice of use show that users continuously need to engage with the contingencies of the machine - such as failures or breakdowns - and do workarounds and context dependents decision making in situ. While extensions or improvements 
to the 3D printer are valuable, there is need to further understand the everyday engagements around these machines and the specific situated and embodied actions that this involves. We therefore explore perspectives of studying machines that concern and have interested scholars in HCI (and related fields) which reach back half a century. This provides a framing to understand interaction around contemporary interactive machines that we see lacking in current literature. To further contextualize our contribution, we discuss recent work on personal fabrication, and particularly how 3D printing has been discussed recently.

\subsection{Studying machines}

Following The study of people's use of machines, in design, interaction, and surrounding practices, is a constituting activity undertaken by HCI scholars since the beginning of the field. Pioneering work in HCI conducted by Suchman, [55] and Orr [39] respectively, attend to photocopiers as machines, people who use them, their interplay and technological demand. The starting point of both their studies was that technology companies (such as Xerox PARC) continued to produce "more complex and versatile machines" that people found even harder to understand and to use [12]. A fundamental conclusion drawn by Suchman was that there was a mismatch between the designers' idea of how plans and prescriptive representations are ideally made and executed, and how they were executed in practice. Here, the notion of situated action with its aim to "explicate the relationship between structures of action and the resources and constraints afforded by material and social circumstances" (p.177) [55] was a major contribution and is since frequently referred to. Suchman relates her argument to Grint and Woolgar [22] who claimed that we have to understand the user of a machine as incorporated "into the sociomaterial assemblage that comprises a functioning machine" (p.190) [55]. According to Suchman "the user however needs to be figured in a less rationalistic manner, than what was common at the time" and the object [machine] as more deeply ambiguous to include various sites, imaginaries, needs and practices (p.193) [ibid]. We pick up on this notion and make use of it by analyzing the 3D printer as such a complex and often ambiguous machine. This resonates with the data collected in our study and is further developed in our discussion.

When circling around the same object of study, hence the development of photocopiers at Xerox PARC, Orr studied how technicians made sense of their work around maintenance through a range of different ways of talking about the machines [39]. Orr saw the sense-making endeavors the technicians displayed, and the "war stories" they were famous for within the cooperation, as a culture in its own right. Furthermore, Orr characterized the technicians practice as comprised of a form of continuous and highly skilled improvisation, a notion our findings resonate with. He sees the embodied practices of technicians as "necessarily improvised and centered on the creation and maintenance of control and understanding” (p.161) [ibid]. These accounts bring to fore that people's relations to and experiences with machines are contingent and situated. In Pickering's work on developing notions of machine and human agency, he describes machines as the "balance point, liminal between the human and nonhuman world" by being situated between the worlds of science, technology and society (p.7) [44].
Pickering writes "[Humans] adopt a passive role, monitoring the performance of the machine to see whatever capture of material agency it might effect [sic!]". He continues: "Symmetrically, this period of human passivity is the period in which material agency actively manifests itself. Does the machine perform as intended? (p.21) [44]. Pickering uses the notion of accommodation and resistance to describe this "dance of agency" between human and machine, in that machines may 'accommodate' some human intentions, but 'resist' others, and the other way around. Rose and Jones note on the work of Pickering that: "This is not to attribute anthropomorphic properties to machines, but to recognize that some human intentions fit more easily than others with the design trajectories of the machines and their influence displayed in organizational implementations. Humans for their part may also resist or accommodate machine agency, recognize these traits in others, and focus them towards their own intentions" (p.37) [47]. In the discussion, we draw on these perspectives on interaction with machines as being inherently situated, where improvisation and adaptation must be understood as an integral dimension of practice.

\subsection{Personal fabrication}

As often highlighted, the 3D printer comes with the promise of "a machine that could make (almost) anything" [29] and only requires 'a push of a button', despite both research and practice showing that interactions with a 3D printer require far more than that. The 3D printer also stands out as a piece of machinery or "emblematic technology" [8] that has come to symbolize the maker movement as well as futuristic promises of personal fabrication $[16,26,53]$ as well as towards alternative and novel ways of production $[7,15,41]$. Personal fabrication ${ }^{1}$ is according to Gershenfeld understood as the manufacturing of a product using a personal computer, digital data, and a printer that can produce three-dimensional solid objects [17]. Research in personal fabrication, however is both niched and simultaneously scattered as it appeals to scholars from varied disciplines and fields such as e.g. HCI, STS, design research, material science, computer graphics and ubiquitous computing to name a few.

The dominant body of research around 3D printing and personal fabrication in $\mathrm{HCI}$ is aiming towards the advancement of the printer and the printing process $[1,36,42,48,49,62]$, materials to be used $[25,40,43,57]$, includes the modifying or tailoring of machines $[15,41]$ as well as possible application areas, as mapped out in [35] and [3]. As Baudisch and Mueller highlight, it is not fabrication that is novel as the technology itself is old, but novel is that it is personalized and therefore appearing in new contexts [3]. The continuous development of 3D printing technology makes 3D printers cheaper and more reliable, offering promises - as described earlier - but also opening for diverse and novel ways of manufacturing $[20,21,53]$, thriving in hobby and maker settings [24, 48, 50], as well as applied within domestic use [52]. In recent personal fabrication discourse, scholars problematize how 3D printing may be useful for consumers (such as everyday end-users) and what such a transition would entail. Baudisch and Mueller [3] highlight four

\footnotetext{
${ }^{1}$ Personal fabrication and digital fabrication are often used interchangeably. We decided on "personal" as it highlights the individual involvement of users with the machinery and puts less emphasis on its digital quality.
} 
elements to get 3D printing technology ready: (1) machines and materials that allow consumers to fabricate the intended object in the first place, (2) software that embodies 3D printing domain knowledge, (3) software that embodies the know-how required to operate the machinery and (4) software that provides immediate feedback and supports interactive exploration (p.5) [ibid]. While we agree that technology needs to mature and that software plays an integral part in assisting the 3D printing process, hence the research agenda Baudisch and Mueller indicate above, and similarly approached by several other scholars as presented below, this will still be challenged through practice, as we show in our findings and discussion. If 3D printing indeed has a future and would turn into a common household appliance, such as printer/copiers have been in the previous decades, a nuanced understanding of the practices around its use will be crucial for interaction designers who are operating in this domain. Here we argue however that there is a need to articulate what is going on between the practitioner and the machine, as well as the design that is $3 \mathrm{D}$ printed and we also need to find ways to unpack how these are interrelated.

\subsection{D printing practice}

Several scholars have started to highlight various strands of 3D printing by addressing use and practice. Ludwig and colleagues have in a series of studies explored different angles of how users and communities' appropriate 3D printers. Here they studied practices and usage behaviors during 3D printing and identified design challenges and implications that challenge this practice, much like the findings we collected in our study [32]. According to the scholars most of the practices users reported on were highly socially embedded in the sense that the appropriation of the machinery was strongly enabled by cooperative informal learning and coordination in the context of playful experimentation. Further, Ludwig et al. developed the concept of social technologies, which "aim to provide a secondary layer of interaction functionalities to support users in their 3D printing endeavors (p.24) [30]. Here, they claim to make use of the possible ubiquity of $3 \mathrm{D}$ printers by integrating supportive data into the technology itself, otherwise gathered socially through community sharing. While first relying on IoT technologies (i.e. added or integrated sensors), that can help users to overcome appearing problems [30], the scholars then moved on to visualization and introduced projection mapping as a method to support appropriation of complex hardware-centered technologies [31].

In a different study, Hudson and colleagues [24] examined the approaches newcomers take to 3D printing. The scholars particularly highlight the importance of the practitioners' understanding of the workflow and recommend that "future fabrication tools should consider the interdependencies within a casual maker's workflow and the social nature of the walk-up-and-use 3D printing process" [ibid:393]. Similarly, Fossdal et al. argued for a need to "enable users without expertise in machine design but with application and domain expertise to develop their own novel machines" (p.412) [15]. Here the researchers developed an open-source toolkit, as a result from a series of work on novel fabrication machines, that aims to provide scaffolding and infrastructure for designing and customizing of these types of machines [ibid]. Others, such as Hofman et al. explored the need for tools that explicitly use an end-user program perspective [23]. In their framework PARTs, they provide users with tools that provide familiarity but not expertise of CAD software, to facilitate design intent and reuse of 3D designs.

As shown above, much of the research on 3D printing practice in $\mathrm{HCI}$ is concerned with identifying use challenges and providing technological and infrastructural support or solutions, either through software $[3,23]$, integrated technological fixes to improve the workflow [24] or by social infrastructuring of 3D printing practice $[30,32]$. Another strand of research is more concerned with looking at the particularities of 3D printing as a practice and the challenges that practitioners face. Here Dew et al. [9] for example addressed the alignments of the printing process and drew attention to overlooked printing experiences that may not be technologically solved, but require in-situ negotiations and judgments instead. In a follow-up study, Dew and Rosner then attended to the waste of 3D printing practice and explored how designers might conceive, handle, and rework these leftovers of fabrication tools through tactics of ecological inversion [10]. Our findings align with Dew et al.'s [9] approach and aim to further develop understandings of $3 \mathrm{D}$ printing practice by explicitly focusing on the situated and embodied dimensions of 3D printing activities.

\section{METHOD}

The conversations around 3D printing presented in this paper derive from data collected at a one-day workshop on 3D printing practice with a focus on discarded and failed artifacts. We also draw on observations of practice in the 3D printing room of a communitydriven makerspace as part of a two-year ethnographic involvement with the site, where 3D printers stood out as machinery that played an important role in the makerspace activities. Observations of 3D printing practice then showed a high frequency of mistakes and failures, where printed artifacts did not turn out as expected, machines broke down and used materials showed different behaviors than makers anticipated. Particularly interesting was the plethora of wasted filament as well as the amount of unsuccessful and discarded objects that ended up in the makerspace trash bins. Inspired by this observation, we installed a box in the makerspaces printing room for the duration of six-months, where makers could voluntarily dispose of their failed prints as an alternative to throwing them away [see fig. 2]. The assortment was limited to plastic objects (PLA, ABS and nylon) and all printed on the four then available desktop 3D printers (with FDM technology) at the observed makerspace.

We then used a selection of the assortment [see fig. 3] and the first and second author conducted a workshop on 3D printing practice, inviting a group of nine practitioners from maker-, industry- and university contexts, which were recruited openly by sending out invitations to people active in makerspace network as well as at multiple universities with active makerspace initiatives. With the only requirement being that the participants should have some previous experience in 3D printing, we ended with a group of nine $3 \mathrm{D}$ printing practitioners with varied expertise (2 with limited expertise, 4 with moderate expertise and 3 with deep expertise). This provided us with a diverse sample of how people make use and sense of the desktop 3D printing process. The participants 


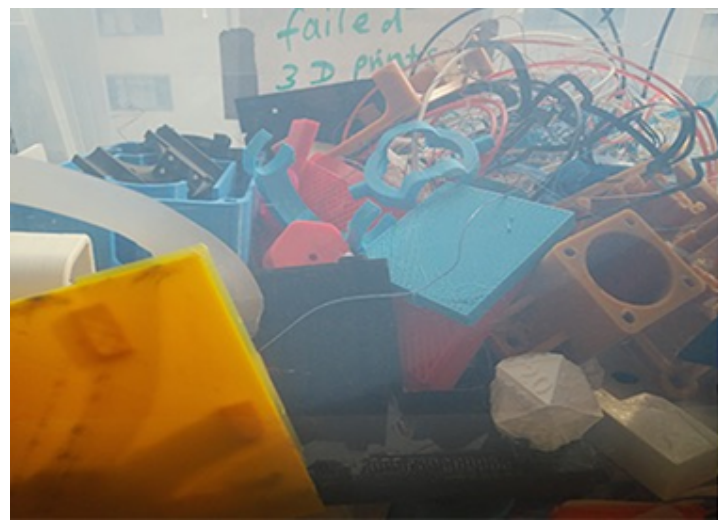

Figure 2: The assortment of failed prints in box

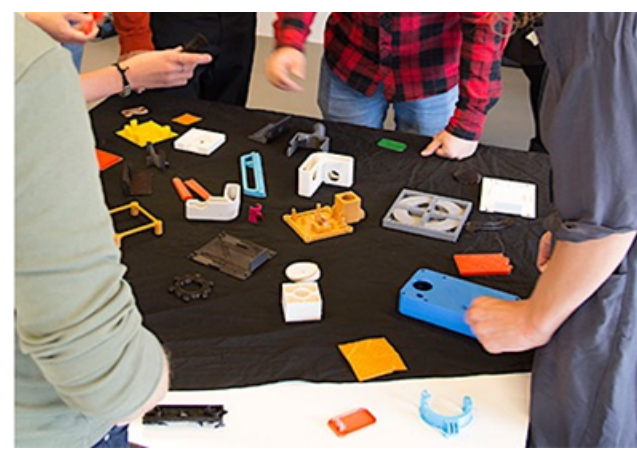

Figure 3: The artifacts on display at the workshop.

had various relations to 3D printing, reaching from makerspace practice (2), to hobbyist and artistic practice (2), to prototyping and design work (3) as well as practitioners who use 3D printing as part of professional work (2) [see table 1 for further details, including level of expertise]. At the workshop, we asked the participants to pick examples from the previously collected failed prints [fig. 3], which were then discussed and reflected upon in smaller groups. All activities were documented in video- and audio recordings (resulting in $6 \mathrm{~h} 10 \mathrm{~min}$ of recorded material). Additionally, 264 pictures were taken for documentation and 30 pictures were taken afterwards to visualize the chosen artifacts our participants refer to in their conversations.

The activities in the workshop played out as follows: First we asked the participants to pick an artifact from the assorted failed prints, which were placed on a central table. While inspecting, touching and comparing the different artifacts on display [see fig. 3] some participants began right away to mention discovered qualities, like P4: "This one really has a texture, very different from the other ones". Others showed aesthetic appreciation of particular artifacts: "Cause' this is gorgeous", "I love these" (P3), or by exclaiming: "This one is the best" (P8). We then had the participants split into two groups, where we ensured a variety of 3D printing experience and asked them to discuss their chosen artifact. This resulted in nine separate stories around ten discarded artifacts and led to conversations and collective sense making around the artifacts and its corresponding characteristics, presented in our findings.

Key empirical material discussed in this paper are therefore the conversations around failed and discarded 3D printed artifacts that derived from the workshop. Data from the longitudinal ethnographic study is not explicitly presented in this paper, thus provided us both with an analytical direction, and contributes to the conceptual work we are mapping out here. During analysis, we iteratively reviewed the empirical material by using inductive analysis techniques and a grounded theory approach [7]. We coded the transcript and analyzed the data by looking for interdependencies between reflections on material, machine and design as well as for accounts related to the participants' experience and expertise they demonstrated in the conversations. Leading inquiry was: How do the participants make sense of the failed artifacts? We also analyzed the dialogue structure regarding to how the participants show understanding, reason and how they explain what they see to each other. Here we make a point of the fact that the participants don't relate to their own failed prints but reflect on artifacts made and discarded by other makers. We argue that their interpretations shed light on both their own experience and expertise of 3D printing as well as they reflect on others more generally. Methodologically, we align our work to similar approaches within HCI research such as material speculation and critical inquiries - which utilizes physical artifacts to generate possibilities for reflection [58] as well as the concept of material literacy [28], which highlights the relationship between the subjects' skills and motivations to understand and interpret material and objects at hand. Like Wakkary and colleagues concept of material speculation, we also see a centrality in the actual and situated artifact as a producer of knowledge which can act as an essential contributor in interaction design research [58].

\section{FINDINGS}

The $3 \mathrm{D}$ printing process can be described as a straightforward workflow on the one hand and as complex and as susceptible to failure on the other. This duality is deceptive as it suggests easy access and possibilities to fabricate an artifact, but the materials and machines often demand a more integral involvement throughout. As we made use of explicitly 'failed artifacts' as tactile tokens we asked the workshop participants to reflect on different things that can go wrong throughout a printing process. To structure our findings, we first display examples of common failures that impact and disrupt the $3 \mathrm{D}$ printing process as reflected in the conversations we collected. We then move further to highlight three themes that emerged, which forefront the situated and embodied interactions practitioners enact when handling a 3D printer. These are i) assessing printability before printing, ii) monitoring and intervening during a print and iii) reading the resulting prints after the printing process. As becomes visible, the themes mirror the printing process workflow, which is intentional as it helped us structuring our findings. This then leads to our conceptual contribution of 'machine sensibility' which we first saw appearing in the common failures and which we identified more deeply in all three themes. 
Table 1: Workshop participants at a glance

\begin{tabular}{|c|c|c|c|}
\hline & Identifiers & Profession & $3 \mathrm{D}$ printing expertise \\
\hline P1 & $\begin{array}{l}\text { Male, } \\
\text { late 20s }\end{array}$ & $\begin{array}{l}\text { 3D printing consultant and educator } \\
\text { with background in maker community }\end{array}$ & $\begin{array}{l}\text { Deep expertise, working " } 24 \text { hours" with 3D printing, highly skilled but } \\
\text { self-trained with years of experience }\end{array}$ \\
\hline P2 & $\begin{array}{l}\text { Male, } \\
\text { early } 30 \text { s }\end{array}$ & $\begin{array}{l}\mathrm{PhD} \text { student in } \mathrm{HCI} \text {; Industry design } \\
\text { and engineering background }\end{array}$ & $\begin{array}{l}\text { Moderate expertise, Specific knowledge of modeling in CAD, used } \\
\text { printers before for industry design projects }\end{array}$ \\
\hline P3 & $\begin{array}{l}\text { Female, } \\
\text { mid } 40 \text { s }\end{array}$ & $\begin{array}{l}\text { Educator and social worker employed } \\
\text { by the city }\end{array}$ & $\begin{array}{l}\text { Deep expertise, but hobbyist practitioner, works in her free time with } \\
\text { female maker initiatives }\end{array}$ \\
\hline $\mathrm{P} 4$ & $\begin{array}{l}\text { Male, } \\
\text { mid 20s }\end{array}$ & $\begin{array}{l}\text { PhD student in HCI, design } \\
\text { background }\end{array}$ & $\begin{array}{l}\text { Limited expertise, tried 3D printing in university projects, interested in } \\
\text { sustainability questions }\end{array}$ \\
\hline P5 & $\begin{array}{l}\text { Male, } \\
\text { early } 50 \mathrm{~s}\end{array}$ & $\begin{array}{l}\text { 3D printing technician, owns a } \\
\text { company on prototype and model } \\
\text { making }\end{array}$ & $\begin{array}{l}\text { Deep expertise, works with industry 3D printers professionally, uses } \\
\text { desktop machines for playful, hobbyist explorations }\end{array}$ \\
\hline P6 & $\begin{array}{l}\text { Female, } \\
\text { early } 30 \text { s }\end{array}$ & $\begin{array}{l}\mathrm{HCI} \text { PhD student, background in art } \\
\text { and fashion design }\end{array}$ & Moderate expertise, has used 3D printing for design practice \\
\hline P7 & $\begin{array}{l}\text { Male, } \\
\text { mid } 40 \text { s }\end{array}$ & University lecturer in game studies & $\begin{array}{l}\text { Moderate expertise, hobbyist practitioner of model making, } \\
\text { learning-by-doing approach }\end{array}$ \\
\hline P8 & $\begin{array}{l}\text { Male, } \\
\text { late } 20 \text { s }\end{array}$ & $\begin{array}{l}\text { PhD student in } \mathrm{HCI} \text {, background in } \\
\text { engineering }\end{array}$ & Limited expertise, interested about 3D printing as a process \\
\hline P9 & $\begin{array}{l}\text { Male, } \\
\text { early } 30 \text { s }\end{array}$ & Self-employed designer and lecturer & $\begin{array}{l}\text { Moderate expertise, prototyping with 3D printers, design and process } \\
\text { related interest }\end{array}$ \\
\hline
\end{tabular}

\subsection{Common failure in 3D printing}

The following examples illustrate different types of failure that commonly occur in desktop 3D printing. We see these as glimpses into printing practice, that helps us make sense of the many things that can go wrong and break down in ongoing 3D printing processes. Scholars, such as Ludwig et al. [32] and Hudson et al. [24] among others have identified similar challenges when interacting with 3D printers. Additionally, many of these are addressed in manuals, tutorials and how-to videos, common and widely spread in 3D printing and maker communities. The accounts taken up here are therefore not of novel, but of generalizable character. We argue however, that the processes involved are not simply about optimizing settings and decision making during the printing process. What we contribute with in this paper - and what is less accounted for is the situatedness of these actions, and how every single machine and printing process unfolds in unique ways.

These exemplary accounts above (in table 2 ) show that the $3 \mathrm{D}$ printing process is afflicted with contingencies where failures and breakdown occur. While the notions of temperature and time are external conditions that influence the process, the other aspects highlighted by our practitioners shed light on mistakes conducted by either the human in handling the machine (such as slicing mistakes or faulty positioning) or the machinery performance (such as attention to material behavior or an unintended appearance). Quite often, this relation moves back and forth, between the human and the machine; hence between human activity and passivity on the one side and machinery and material performance on the other. What becomes prominent in the accounts shown in the table above is that embodied and situated dimensions are important in all types of failures discussed. This aligns with previous work by for example Ludwig et al. [30] who points to the situational and context dependent nature of the printing process, and how prints may be affected by actions such as opening a window while the printing takes place. In the next section, we will explicitly analyze how these dimensions are manifested in activities before, during and after a 3D print.

\subsection{Before the printing: Assessing printability}

The first theme we identified, points to an awareness of the intricate and complex interplays between the software design, the workings and situatedness of the machine and the materials used in the process. Assessing the "printability" of a design is something they consider when starting off a printing process, already from the initial stage of the idea generation, through creating the 3D CAD design (see fig. 4), while deciding on the setup, as well as in the use of a specific machine. One of the more experienced practitioners, P1 states that there are things to consider on "how to design, and to design well for $3 D$ printing. But that it also depends on the kind of printer". Being able to assess printability as the practitioners show,

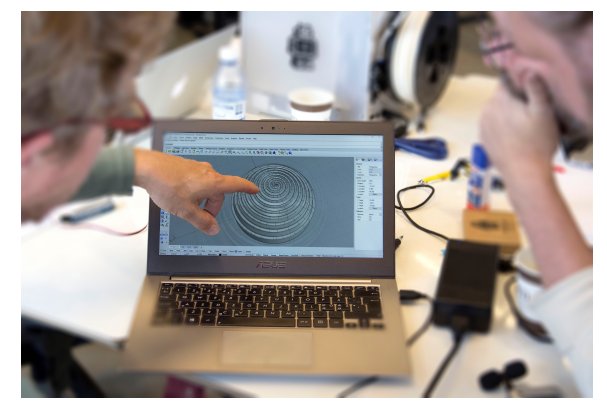

Figure 4: (left) Practitioners discuss printability of a CAD model. 
Table 2: Overview of common failures in 3D printing

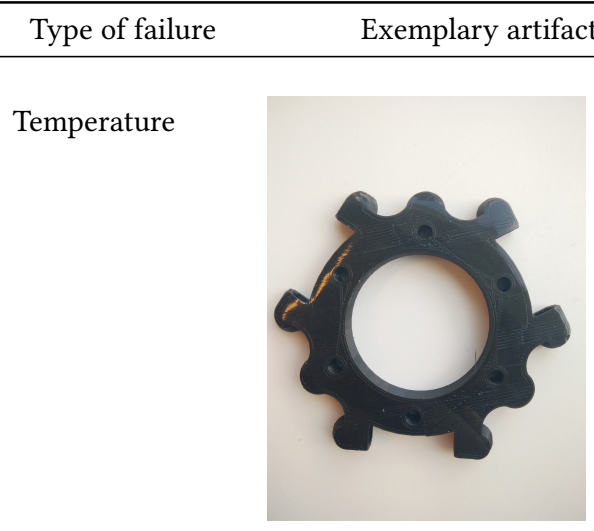

Time

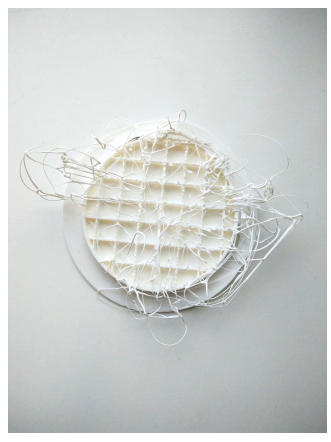

Material

behaviour

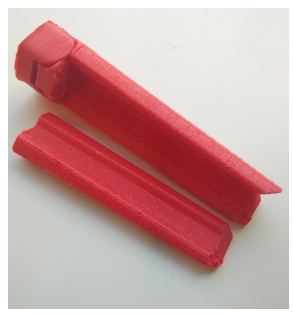

Material appearance

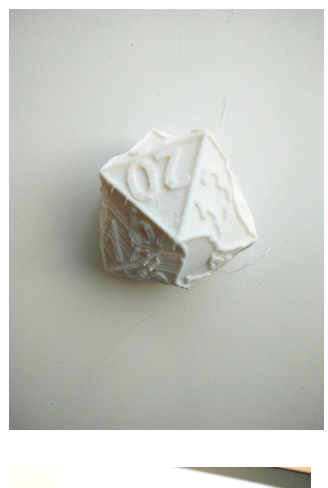

Slicing mistakes

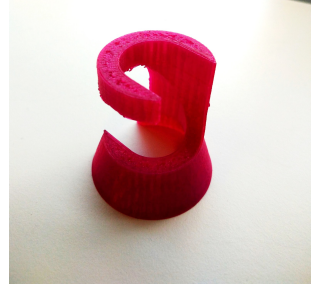

Heat errors are a common source of failure in $3 \mathrm{D}$ printing. If the temperature is too high it can burn and get stuck, if it is too low it can block the nozzle. The practitioners commonly reflected on material behaviors due to temperature variations, such as "A five or ten-degree difference in the extruder temperature can be the difference between a perfect print and a failed print" (P1). This highlights an awareness of how the plastics used in 3D printing are highly sensitive to variations and changes of temperature. Similarly, practitioners identified certain "heat errors", as reoccurring problems during the printing process. Others mentioned temperature as reasons for how the shape of artifacts could get problems "in the lamination process" and objects ended up "warped" (as seen in the figure).

Another source of failure is due to time restraints and expectations on how long 3D printing takes. One practitioner stated, "there is a lot of time invested". P3 explained that novice users are often rushed, imitating: "Oh, this is gonna take a day and a half - then they make it really thin or without support [...] And then they end up doing it four times". According to P5 rushing can also lead to problems during material extrusion (see figure to the left). Other examples pointed to perceived limitations of the machine in connection to the outset design: "And it really hadn't the time to fill in all the holes yet". P3 also points towards prints "that require work 24/7", especially when produce larger printing sizes or volumes.

Some of the printed artifacts lacked overall quality. Here practitioners expected flexibility "whoever did this, expected it to be more elastic, so as soon this was pushed, it broke off" (see figure to the left) as well as commenting on durability "this needs to be more solid" or "this broke apart and were disconnected when used". The quality of the resulting print is often related to undesired material behavior, such as not getting "a perfect layer or bottom adhesion to the print plate" producing a flawed build-up from the start. Hence, they linked print and material qualities to decisions made during different moments of the printing process.

While evaluating the apparent form and shape of the failed prints, the practitioners argued for example that "the finish isn't the best over here", or that parts were "not perfect on any of the surface layers". P3 wondered if an artifact "was initially designed that way" or if failure happened during the printing process. Other participants hypothesized that their artifact was "slightly shifted" (see figure to the left), another assumed that his artifact turned out with the "wrong color" and that the surface and parts of the structure was "flawed". All these reflections related to the artifacts' appearance.

As slicing of the design is a software process, where the CAD design is translated as coordination which a 3D printer can understand and print, problems occur mostly as wrong decisions are made by the user. Here P1 claimed that in the artifact (to the left) the "top layer seemed to be flawed" which according to him could depend on problems during the slicing process, where the print ended up with "one top layer, instead of like six or seven. So, it gets way too thin". Testing and tweaking the slicing settings were repeatedly brought up as an important step before translating the digital design to a printable version, and if disregarded it just "does not hold up". 
Issues with positioning and support structures

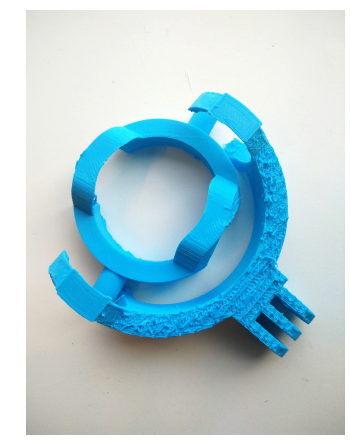

Some examples pointed towards the importance of the exact positioning and the support structures used, and how this was considered already in the design stage. Position in the printer was often mentioned, e.g., "it moved while it was printed" (P2), as a reason for things going wrong. The lack of support to ensure adhesion to the build plate or users choosing the wrong types of support "Here they should have used more support rows" were also typical things identified. P5 provided an example of what might happen when positioning is not considered: "If you print a " $U$ " standing upright, it's gonna move inwards like this, because of the corners here" (see figure to the left). Decisions made within these steps, such as picking correct support structures, often require iterative testing as P3 recollects "you try until something works".

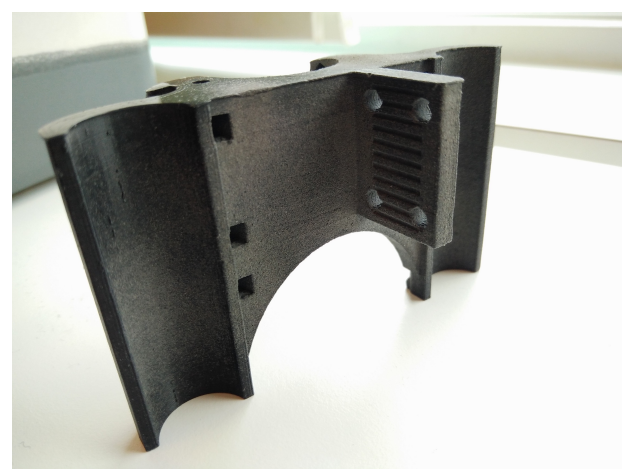

Figure 5: (right) Artifact with overhanging parts.

helps to avoid mishappenings during the actual printing process. He continues: "if you learn the design rules of an efficient $3 D$ print, like how would you get a high probability of the system working well and not wasting the material [...], so if you learn the design rules, you get a much better print and lose less material'. The artifact, picked by $\mathrm{P} 2$ is a rectangular object, with concave bits and stabilizers (see fig. 5). P1 uses this to highlight, how positioning of a CAD design matters to receive a printable object: "...If you would have this printed this like this [showing position as in fig. 6] it would have needed support structures under here and you would have needed support under here as well [pointing out overhanging bits], which you have to cut away afterwards". Especially practitioners with deep expertise (P1, P3 and P5) reflect on how initial decisions are made and how these may shape and impact the print throughout the process. Practitioners distinguish between efficient and inefficient prints, based on how well design rules were followed (or neglected) and decisions are made during the slicing and setup of the machine. While design rules are common in 3D printing handbooks and tutorials, the conversations in our study show that they require hands-on experiences of the materials and the machines in order be effectively put into use. Practitioners also reflected that the digital form often differs substantially from the finished prints.

Further the practitioners agree that there are various ways of succeeding as well as failing with a $3 \mathrm{D}$ print. What qualifies as printable - i.e., assessed for being successfully printed - depends largely on the user's level of experience, and competence to navigate between

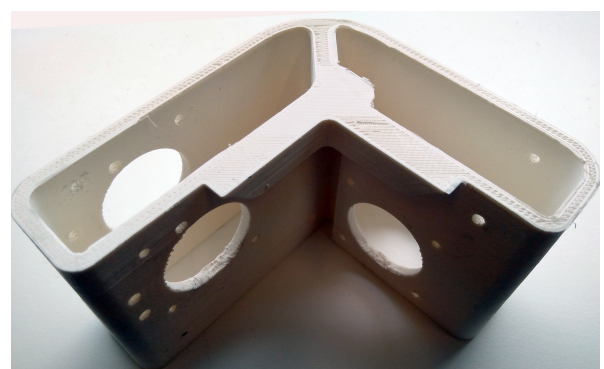

Figure 6: Surfaces and walls close-up. the workings of the machine, the qualities of the print materials, and the prints later purpose. In a conversation of different character, P3 shared a "war story" of a fellow practitioner who got a 3D printer to work better by "tilt[ing] the entire machine on a bent 45-degree angle. So, there [a successful print] involves that the complete machine is tilted as there was no way to fix it otherwise". The scholar Orr describes similar narratives around machine diagnostics as a starting point for technicians' talk about their experiences and how these serve as "means for the social distribution of experiential knowledge through community interaction" [39]. P3's example shows that printability is both of relevance within the digital phase of creating and working with a CAD design, but also by linking it to the contingencies of the machine. However, this goes both ways, as estimates of the workings of the machine also influence what is required in the design phase in the first place. Considerations of these relationships are continuously something that designers must engage in. This practice of making educated guesses for how a print will come out is important and sensibilities around the workings of 3D printers play a critical role in identifying and avoiding potential faults that may occur throughout the printing process. A print of the same design could fail on one occasion and not on another, depending on small variations in temperature, choice of plastic, and the requirement of support structures, as the examples in 4.1 show. While one purpose of this competence may be to avoid failure during the actual printing process, the considerations and estimates of the machine may also influence more fundamental design decisions. 


\subsection{During the printing: Monitoring and intervening}

As second theme, we discuss the practitioners' conversation about the printing process with respect to the autonomy of the machine, the comparatively time-consuming printing processes and various ways that workflows may go wrong in an ongoing print and ways of interfering.

The $3 \mathrm{D}$ printer is a machine that makes it possible to closely observe and monitor the actual manufacturing process. It runs autonomously and is not intentionally designed to be interacted with during the actual printing process: that is when the machine is extruding filament onto the build plate and building a physical artifact according to the previously designed coordinates. Here the machine is 'doing its thing' and thus black boxing the process, requiring the practitioner to accept the printed result. Similarly, Ludwig et al. state that "one shortcoming of the 3D printer is that it's a kind of black box for users and lacks in the provision of methods or descriptions of functionality that might help the user to visualize how it works" (p.13) [30]. One way to overcome the machines' autonomy would be to monitor the ongoing process more closely and find ways to interfere if necessary. Our practitioners suggest putting up web cameras and sensors to monitor how things unfold. P3: "I mean people do that, you can attach a camera up there in the corner. [...] More for monitoring". P2 replies that he would instead of a camera suggest "some sensors and actuators that measure the vibration, where you get direct feedback on small scale changes. When the prints then [fail] and the check is on, you can like...turn it off." These examples suggest rather technical fixes to provide more assurance of an ongoing printing process than manually intervening.

Notably though, in our observed conversations, there were multiple examples where practitioners referred to ways of intervening the 3D printers' autonomy in more subtle ways. In one conversation P3 reflected over how to respond to failures when appearing during the process which she has experienced previously herself: "Do I leave it two more hours and see how it works out?" or do "I see what happens - and in the end, it maybe survives another hour." Here, P3 refers to a process of taking chances by "waiting to see if a print will self-correct and heal", or if the artifact "didn't move that much" in the end than first anticipated. Thus, this skilled practice is described as a process of continuously engaging with and interpreting the current state of the print (including the printed quality, behavior of support structures or the 3D printer's axis direction) and making decisions about the machines' action and proposed result. In another instance, our practitioners reflected about stopping the printing process, adding something to the object, as well as trying to correct small errors that occur during printing. For instance, P3 described: "I have definitely picked off some of the melted plastic and pushed like a blob of plastic underneath to just see what happens. Sometimes the act of picking off destroyed the whole thing...so there are many ways to fail." Consequently, there are trade-offs between on the one hand quick printing with a greater risk of failure and on the other hand preferring a slower process in which attention is given to details and failure prediction.

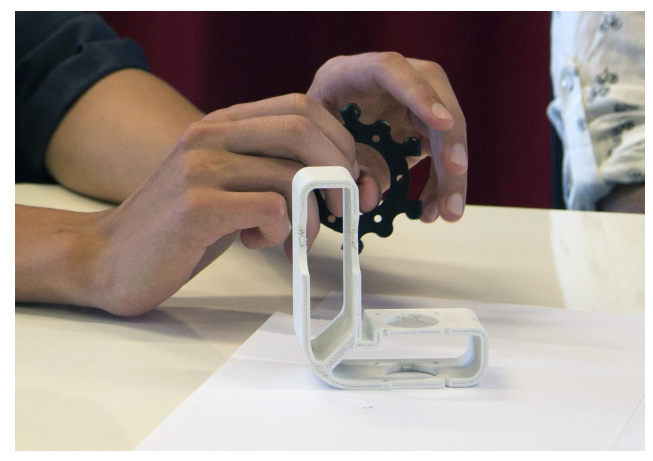

Figure 7: Examining thickness.

We conclude that the sense making of the discarded prints were often made in relation to the time and efforts required of a practitioner to monitor and interpret the state of the printing process while it unfolds. Here the combination of long printing hours and uncertainties in the printing process brings to the fore how $3 \mathrm{D}$ printing practice involves situated engagements with the workings of the machine, that are constantly changing and highly ambiguous.

\subsection{After the printing: Reading prints}

In the conversations around the failed prints accounted for in our data, practitioners display an ability to also "read" and interpret characteristics of the printing process from these provided artifacts. Here considerations reached from the artifacts' design, over the machines' behavior to the prints resulting appearance, as picked up on in 4.1. Yet the practitioners' awareness of possible consequences throughout the whole printing process was key. As a third theme, we therefore point to the practitioners' abilities of reading the printed artifacts.

The fact that 3D prints result in physical artifacts opens for this type of embodied examination and in situ sense-making of the unique traits of each piece. For instance, one practitioner discussed the state of an artifacts' layer structure. P4 started out by asking the more experienced practitioners of the group (P3, and P1) what qualifies as a top layer? P1 replied with a technical answer claiming that layers that are "not [only] horizontal actually, but less than 45 degrees... which are then considered to be top surfaces and all others are considered to be walls" (see fig. 6). P3 continued by picking up another artifact to emphasize its material qualities: "So here you can see and feel the thickness, so this is an outer wall, which is drawn thicker than the lines the machine drew here". P3 here performed a tactile examination of a printed piece (fig. 7) illustrating how to judge if the outer walls were thick enough, by touching and feeling the artifact.

In a related example, the practitioners discussed how 3D printing links to craft practices. P3 claimed that the process of 3D printing is "very much a craft or handwerk [...] in handling the 3D printer and the 3D modelling". $\mathrm{P} 3$ continues "...you have two people who have gone the same education and learned the same things, and one just has a better hand at it. $3 D$ prints come out better, they have a feel for it." Having "a feel" for something is somewhat hard to grasp. Similarly, Orr accounts for these types of skills among copying 
machine technicians as requiring a "kinesthetic awareness of the machine, knowing whether the feel of a given mechanism is right or not" (p.120) [39]. In another example, P2 reflected on a previous experience of crafting with metal where he was trained to sand down a piece in a certain manner: "But there you spent like two or three hours on doing that and you actually feel every millimeter that is taken away and here [in 3D printing] it's just the design, and then you leave it and you get it back and it's messed up. And you're disappointed and then do the next one". Our study shows that the physicality of the 3D printing as a machine, and the resulting tactile engagements with it, are crucial for the development of machine sensibilities. This relates both to kinesthetic awareness as well as the type of craftsmanship mentioned above. The detailed characteristics of printed artifacts made way to draw conclusions on how the printing process played out, as well as to assess the quality of produced print. Similar types of readings of and engagements with tools and materials have previously been brought to the fore in studies on embodied interaction [11,27] and tangible user interfaces [14]. The practitioners' sensibilities to these different experiences were central to their conversations about how to deal with the machine. We here can also relate to the concept of material literacy, which highlights the relationship between a subjects' skills and motivations to understand and interpret material and objects at hand, which the authors have previously worked on [28]. This was especially displayed by practitioners with deep 3D printing expertise. We therefore see their ability for this reading of the artifact or material literacy [28], as an integral part of the sense making processes around 3D printing.

\section{DISCUSSION}

Through this study, we aim to nuance the understanding of practices surrounding 3D printing, where the $3 \mathrm{D}$ printer, although overly hyped in popular media, still has the potential to be disruptive, impacting both the society at large, but also the field of interaction design research and practice. Aspects of interaction in 3D printing practice highlighted by our study are commonly not articulated as critical to the competences of learning and interacting with $3 \mathrm{D}$ printers $[5,24,51]$. The interactions focused on here may include the tangible feel of a material's quality, e.g. how the rough edges of a 3D printed surface may tell the practitioner about the amount of infill or about the printer's performance when producing the artifact's first layers; equally to how the hammering noise or stutters of the machine sounds when the print plate is not perfectly adjusted and the printer's head gets too close to the print plate, possibly resulting in printing failures.

\subsection{Introducing machine sensibility}

To conceptualize these aspects of 3D printing practice we propose the notion of machine sensibility. We use the word machine to highlight the importance of understanding the materiality of the 3D printer as a machine, and sensibility, to point to the number of critical interactions and abilities that surfaced in the study of this practice. By expanding on the three themes found in the analysis, we argue that machine sensibility in the context of $3 \mathrm{D}$ printing practices includes:
- Understanding interdependencies between design, machine, and the physical and digital material: The 3D printing process is multifaceted and varied. Practitioners display awareness and responsiveness to contingencies, such as the machinery inner-workings, its relation to each unique exemplar and consequences of the specific properties of the used materials.

- Relying on experience and embodied sense making: Interpretations of the printing processes and resulting artifacts involve sensibilities to the subtle characteristics of 3D printers, the printing material and the resulting printed artifacts.

- Doing skilled improvisation: Assessments are extensively grounded in previous experiences and practitioners draw on them when engaging in a printing process. Improvisation, educated guesses and skillful workarounds are important parts of the practice of 'making' 3D prints.

- Managing temporality: The specific temporality of 3D printing is central to how practitioners monitor and interpret the unfolding process and make sense before, during and after printing. Current desktop 3D printers require comparably extensive printing times, which fosters actions to monitor and intervene in any ongoing process.

- Reading resulting artifacts: Practitioners explore the detailed characteristics of printed artifacts to draw conclusions on how the printing process played out, and to assess the quality of produced print. The ability for these readings or material literacy are an integral part of the sense making processes around 3D printing.

In summary, practices around 3D printers rely on embodied and situated interactions and abilities. Besides highlighting these as presented above, we argue that the machine sensibility concept also consists of a conceptualization of the 3D printer as a machine. Similarly, Dew et al. argue "while new technical responses can remove some barriers to predictable printing, these are nested within broader embodied and collective sense-making processes that still require ongoing articulation and alignment work" and that "this in turn develops important embodied understandings that practitioners need" [9]. This not only refers to tactile or sensible characteristics of the artifact as such, but the actual judgement also requires experiences of both simplifications and algorithmic assumptions made by the machine, such as calculating different paths and layers before the actual printing starts.

Supported by our data, we suggest two possible points of departure: understanding (1) machine materiality and reflecting on (2) machine agency $[2,44]$ of apparent physical machines and tools in interaction design.

In our findings, we saw that unique properties of each specific machine often must be considered in the process. The materiality of each machine therefore comes into focus, and interactions revolve around the particularities of both the materials and machine used. Material dimensions of 3D printing are not only apparent in relation to its design materials but the printer itself also has a certain materiality, which shapes the design and printing process. This materiality becomes noticeable through the buzzing of the machine axes, rotating wheels, and dragging and adjusting of print plates, that are all typical sounds around a desktop 3D printer. So is the filament and used glue which gives off a distinctive smell when 
melting. Fumes, temperature, and varying demands on filaments require careful treatment and in some cases specific preventive measures must be taken. All this and more makes the 3D printer into a machine, which can be related to and understood. The understanding of machine materiality can be linked to the discourse around the so-called 'material turn' in HCI [46], which puts the focus on how interaction is increasingly mediated through physical materials, and how interaction design researchers need to be concerned with the material conditions in human-computer interaction $[4,18,56,59]$. The material turn shifts attention from discussions about a physical-digital divide, towards the broad reconsideration of materiality within the context of computation [46] and design [18]. Wiberg introduced material-centric HCI, as an approach to interaction design research that is sensitive to qualities of the materials at hand, digital as well as physical [60]. Fernaeus et al. write that: "Aspects of materiality inevitably become an essential element of interaction and interaction design. Here the different materializations that digital representations take, unavoidably affects how they play out in meaning making practices" [13]. In the articulation of machine sensibility above, the machine materiality is manifested in the practitioners understanding of the interdependencies and interplay between digital models, physical materials, and the workings of the machine, as well as in the embodied and sensory oriented sense making process. Previous studies have also highlighted the material and physical dimensions of 3D printing, such as Ludwig et al. who argue that "we are dealing with a more material, hardwarerelated ecology in the case of digital fabrication technologies, and thus need to consider physical material issues in the context of the challenges users encounter" (p.2) [30]. A recent study by Nam et al. [37] also turn towards materiality, by analyzing perceived material properties, as well as meaning and subjective interpretation of $3 \mathrm{D}$ printed artifacts in comparison to mass manufactured objects [ibid]. Through the notion of machine sensibility, we here aim to actively un-abstract the machine in the analysis of the practices surrounding it, and thereby emphasizing the materiality of the machine. We found that 3D printing served as a rich case to explore such materializations.

Machine agency in 3D printing practice is shaped by the autonomous, and partially unpredictable behavior of the printer pointing to how the expectations and predictions of the practitioner continuously need to be aligned with and adapted to the behavior of the machine. In the articulation of machine sensibility above, the machine agency becomes especially prominent in the findings that concern how practitioners deal with temporality and improvisation. Thus we would like to characterize the practitioner's ongoing attempts of making sense of the behavior and outcomes of the machine by borrowing Pickering's notion of a "dance of agency" [44], which points at the interdependencies between human and machine agencies and how this need to be understood as dynamism of forces rather than as separate entities [2]. Here Pickering is attributing agency to materiality and machines, which according to Cooren "does not mean that humans are dispossessed from their strategies, their intentionality, their goal-oriented practices, or even their wit. But what it does recognize is [...] that the world acts on us as much as we act on it, with a principle of symmetry that enjoins us to redefine the way we study it" (p.21) [6]. This also relates to Suchman's take on human-nonhuman relations which

\begin{tabular}{|c|c|}
\hline \multicolumn{2}{|c|}{ Machine Sensibility } \\
\hline $\begin{array}{l}\text { Machine } \\
\text { conceptualisations }\end{array}$ & $\begin{array}{l}\text { Practitioner abilities and } \\
\text { sensibilities }\end{array}$ \\
\hline $\begin{array}{l}\text { Machine materiality } \\
\text { Machine agency }\end{array}$ & $\begin{array}{l}\text { - Understanding inter- } \\
\text { dependencies } \\
\text { - Experiential and } \\
\text { embodied sense making } \\
\text { - Skilled improvisation } \\
\text { - Managing temporality } \\
\text { - Reading resulting artifacts }\end{array}$ \\
\hline
\end{tabular}

Figure 8: The machine sensibility concept

"involve developing a discourse that recognizes the deeply mutual constitution of humans and artifacts, and the enacted nature of the boundaries between them, without at the same time losing distinguishing particularities within specific assemblages" (p.260) [55]. In our study, we highlight how the practitioners are monitoring and interpreting the unfolding process as the machine is doing its thing, and that they sometimes choose to intervene in the process. Many accounts witness of practitioners' improvisation or adaptation according to given situations, which could also be understood in terms of managing machine agency. We hereby suggest that the machine sensibility concept (see visualized in fig. 8) can serve as an analytic lens to practically explore machine materiality and machine agency in other contexts of relevance for interaction design.

\subsection{Limitations}

Machine sensibility emanates from, and has so far only been discussed in relation to 3D printing practices. While the development of desktop 3D printers has made advances since we collected the data for this study, many of these types of machines continue to inhabit makerspaces, schools and homes of technology enthusiasts everywhere. Several existing fabrication machines (such as laser cutters and CNC mills) share some characteristics with the 3D printer. Given similarities such as their shared physical outputs, digital representation and semi-autonomous characteristic, we suggest that the machine sensibility concept becomes directly applicable to these types of machines. We leave the question open to which degree the concept is usable for unpacking other practices involving machines, which could be further explored in a follow-up study. In that case, we suggest however that the concept fits when looking at other 'black box' autonomous machines, (including e.g. AI and machine learning systems) whereas the embodied dimensions are more applicable for machines with a physical embodiment, such as the fabrication machines mentioned above, as well as to robots, drones and other types of UAVs.

\section{CONCLUSION}

Just as copying machines had a prominent role in the early days of $\mathrm{HCI}$, we argue that 3D printers make way and symbolize how machines have returned as a critical ingredient in $\mathrm{HCI}$ and interaction design. These machines highlight both challenges and possibilities 
less prominent in other directions of interaction design. By analyzing the way practitioners talk about failed 3D printed artifacts, this paper sheds light on the embodied and situated interactions involved in this practice. Our study contributes to the field of HCI and interaction design by introducing the concept of machine sensibility, which emphasizes the machine as an entity often abstracted away in favor of software. We argue that the materiality of the physical machine (be it a 3D printer, a computer or other forms of machinery), is an important ingredient of understanding interactions with novel physical and digital artifacts. What we contribute with in this paper - and what is less accounted for - is the situatedness of involved actions, and how every single machine and printing process unfolds in unique ways. The concept can assist practitioners to describe making processes they engage in and provide researchers with a vocabulary to study and refer to these types of practice. We therefore propose that machine sensibility could work as a starting point to explore and make sense of some of the complex issues around the machines that HCI cares for.

\section{ACKNOWLEDGMENTS}

We would like to thank our participants for sharing their time and experiences. We also thank the reviewers and some of our colleagues for their thoughtful, constructive and often necessary feedback in preparing this paper. This work was funded in part by a doctoral grant from the Foundation for Baltic and East European Studies (Östersjöstiftelsen) in Sweden.

\section{REFERENCES}

[1] Rafael Ballagas, Sarthak Ghosh, and James Landay. 2018. The Design Space of 3D Printable Interactivity. Proc. ACM Interact. Mob. Wearable Ubiquitous Technol.2, 2 (July 2018), 61:1-61:21. DOI:https://doi.org/10.1145/3214264

[2] Karen Barad. 2007. Meeting the universe halfway: Quantum physics and the entanglement of matter and meaning. duke university Press.

[3] Patrick Baudisch and Stefanie Mueller. 2017. Personal Fabrication. HCI 10, 3-4 (May 2017), 165-293. DOI:https://doi.org/10.1561/1100000055

[4] Jenny Bergström, Brendon Clark, Alberto Frigo, Ramia Mazé, Johan Redström, and Anna Vallgårda. 2010. Becoming materials: material forms and forms of practice. Digital Creativity 21, 3 (September 2010), 155-172. DOI:https://doi.org/ $10.1080 / 14626268.2010 .502235$

[5] Erin Buehler, William Easley, Samantha McDonald, Niara Comrie, and Amy Hurst. 2015. Inclusion and Education: 3D Printing for Integrated Classrooms. In Proceedings of the 17th International ACM SIGACCESS Conference on Computers \& Accessibility (ASSETS '15), ACM, New York, NY, USA, 281-290. DOI:https: //doi.org/10.1145/2700648.2809844

[6] François Cooren. 2010. Action and Agency in Dialogue: Passion, incarnation and ventriloquism. John Benjamins. DOI:https://doi.org/10.1075/ds.6

[7] Laura Devendorf, Abigail De Kosnik, Kate Mattingly, and Kimiko Ryokai. 2016 Probing the Potential of Post-Anthropocentric 3D Printing. In Proceedings of the 2016 ACM Conference on Designing Interactive Systems, ACM Press, New York, NY, USA, 170-181. DOI:https://doi.org/10.1145/2901790.2901879

[8] Laura Devendorf and Kimiko Ryokai. 2015. Being the Machine: Reconfiguring Agency and Control in Hybrid Fabrication. In Proceedings of the 33rd Annual ACM Conference on Human Factors in Computing Systems, ACM Press, New York, NY, USA, 2477-2486. DOI:https://doi.org/10.1145/2702123.2702547

[9] Kristin N. Dew, Sophie Landwehr Sydow, Daniela K. Rosner, Alex Thayer, and Martin Jonsson. 2019. Producing Printability: Articulation Work and Alignment in 3D Printing. Human-Computer Interaction 34, 5-6 (2019), 433-469.

[10] Kristin N. Dew and Daniela K. Rosner. 2019. Designing with Waste: A Situated Inquiry into the Material Excess of Making. In Proceedings of the 2019 on Designing Interactive Systems Conference - DIS '19, ACM Press, San Diego, CA, USA, 13071319. DOI:https://doi.org/10.1145/3322276.3322320

[11] Paul Dourish. 2004. Where the action is: the foundations of embodied interaction MIT press.

[12] Paul Duguid. 2012. On Rereading Suchman and Situated Action. Le Libellio d'Aegis 8, 2 (2012), 3-11.

[13] Ylva Fernaeus, Martin Jonsson, and Jakob Tholander. 2012. Revisiting the Jacquard Loom: Threads of History and Current Patterns in HCI. In Proceedings of the
SIGCHI Conference on Human Factors in Computing Systems (CHI '12), ACM, New York, NY, USA, 1593-1602. DOI:https://doi.org/10.1145/2207676.2208280

[14] Ylva Fernaeus, Jakob Tholander, and Martin Jonsson. 2008. Beyond representations: towards an action-centric perspective on tangible interaction. International Journal of Arts and Technology 1, 3/4 (2008), 249-267.

[15] Frikk H. Fossdal, Jens Dyvik, Jakob Anders Nilsson, Jon Nordby, Torbjørn Nordvik Helgesen, Rogardt Heldal, and Nadya Peek. 2020. Fabricatable Machines: A Toolkit for Building Digital Fabrication Machines. In Proceedings of the Fourteenth International Conference on Tangible, Embedded, and Embodied Interaction (TEI '20), Association for Computing Machinery, Sydney NSW, Australia, 411-422. DOI:https://doi.org/10.1145/3374920.3374929

[16] Verena Fuchsberger, Martin Murer, Manfred Tscheligi, Silvia Lindtner, Shaowen Bardzell, Jeffrey Bardzell, Andreas Reiter, and Pernille Bjorn. 2016. Fabrication \& HCI: Hobbyist Making, Industrial Production, and Beyond. In Proceedings of the 2016 CHI Conference Extended Abstracts on Human Factors in Computing Systems (CHI EA '16), ACM, New York, NY, USA, 3550-3557. DOI:https://doi.org/10.1145/ 2851581.2856491

[17] Neil Gershenfeld. 2012. How to make almost anything: The digital fabrication revolution. Foreign Aff.91, (2012), 58.

[18] Elisa Giaccardi and Elvin Karana. 2015. Foundations of Materials Experience: An Approach for HCI. In Proceedings of the 33rd Annual ACM Conference on Human Factors in Computing Systems (CHI '15), ACM, New York, NY, USA, 2447-2456. DOI:https://doi.org/10.1145/2702123.2702337

[19] Sharona Ginsberg. 2012. 3D Printing and Creative Literacy: Why Maker Culture Benefits Libraries. Everything You Wanted to Know About Information Literacy But Were Afraid to Google (2012), 89.

[20] David Philip Green, Verena Fuchsberger, David Kirk, Nick Taylor, David Chatting, Janis Lena Meissner, Martin Murer, Manfred Tscheligi, Silvia Lindtner, Pernille Bjorn, and Andreas Reiter. 2017. Open Design at the Intersection of Making and Manufacturing. In Proceedings of the 2017 CHI Conference Extended Abstracts on Human Factors in Computing Systems (CHI EA '17), ACM, New York, NY, USA, 542-549. DOI:https://doi.org/10.1145/3027063.3027087

[21] David Philip Green, Verena Fuchsberger, Nick Taylor, Pernille Bjørn, David Kirk, and Silvia Lindtner. 2019. Introduction to This Special Issue on Open Design at the Intersection of Making and Manufacturing. Human-Computer Interaction (April 2019), 1-10. DOI:https://doi.org/10.1080/07370024.2019.1591960

[22] Keith Grint and Steve Woolgar. 1997. The machine at work: technology, work, and organization. Polity Press, Cambridge, UK; Malden, MA: Blackwell Publishers.

[23] Megan Hofmann, Gabriella Hann, Scott E. Hudson, and Jennifer Mankoff. 2018. Greater Than the Sum of Its PARTs: Expressing and Reusing Design Intent in 3D Models. In Proceedings of the 2018 CHI Conference on Human Factors in Computing Systems (CHI '18), ACM, New York, NY, USA, 301:1-301:12. DOI:https: //doi.org/10.1145/3173574.3173875

[24] Nathaniel Hudson, Celena Alcock, and Parmit K. Chilana. 2016. Understanding newcomers to 3D printing: Motivations, workflows, and barriers of casual makers. In Proceedings of the 2016 CHI Conference on Human Factors in Computing Systems, ACM, 384-396. Retrieved from http://dl.acm.org/citation.cfm?id=2858266

[25] Alexandra Ion, David Lindlbauer, Philipp Herholz, Marc Alexa, and Patrick Baudisch. 2019. Understanding Metamaterial Mechanisms. In Proceedings of the 2019 CHI Conference on Human Factors in Computing Systems (CHI '19), ACM, New York, NY, USA, 647:1-647:14. DOI:https://doi.org/10.1145/3290605.3300877

[26] Tom Jenkins and Ian Bogost. 2015. Escaping the Sandbox: Making and Its Future. In Proceedings of the Ninth International Conference on Tangible, Embedded, and Embodied Interaction (TEI '15), ACM, New York, NY, USA, 29-32. DOI:https: //doi.org/10.1145/2677199.2680558

[27] Scott R. Klemmer, Björn Hartmann, and Leila Takayama. 2006. How bodies matter: five themes for interaction design. In Proceedings of the 6th conference on Designing Interactive systems, ACM, 140-149. Retrieved March 22, 2016 from http://dl.acm.org/citation.cfm?id=1142429

[28] Sophie Landwehr Sydow, Jakob Tholander, and Martin Jonsson. 2017. "It's a Bomb!" - Material Literacy and Narratives of Making. In Proceedings of the 2017 CHI Conference on Human Factors in Computing Systems (CHI '17), ACM, New York, NY, USA, 121-132. DOI:https://doi.org/10.1145/3025453.3025529

[29] Hod Lipson and Melba Kurman. 2013. Fabricated: the new world of $3 D$ printing. John Wiley \& Sons, Indianapolis, Indiana.

[30] Thomas Ludwig, Alexander Boden, and Volkmar Pipek. 2017. 3D Printers As Sociable Technologies: Taking Appropriation Infrastructures to the Internet of Things. ACM Trans. Comput.-Hum. Interact.24, 2 (April 2017), 17:1-17:28. DOI:https://doi.org/10.1145/3007205

[31] Thomas Ludwig, Michael Döll, and Christoph Kotthaus. 2019. "The Printer is Telling Me about Itself": Supporting the Appropriation of Hardware by Using Projection Mapping. In Proceedings of the 2019 on Designing Interactive Systems Conference - DIS '19, ACM Press, San Diego, CA, USA, 331-344. DOI:https://doi. org/10.1145/3322276.3322342

[32] Thomas Ludwig, Oliver Stickel, Alexander Boden, and Volkmar Pipek. 2014. Towards sociable technologies: an empirical study on designing appropriation infrastructures for 3D printing. In Proceedings of the 2014 conference on Designing interactive systems, ACM, 835-844. Retrieved from http://ll.acm.org/citation.cfm? 
id $=2598528$

[33] David Mellis, Sean Follmer, Björn Hartmann, Leah Buechley, and Mark D. Gross 2013. FAB at CHI: digital fabrication tools, design, and community. In $\mathrm{CHI}$ '13 Extended Abstracts on Human Factors in Computing Systems (CHI EA '13), Association for Computing Machinery, Paris, France, 3307-3310. DOI:https: //doi.org/10.1145/2468356.2479673

[34] Catarina Mota. 2011. The Rise of Personal Fabrication. In Proceedings of the 8th ACM Conference on Creativity and Cognition (C\&C '11), ACM, New York, NY, USA, 279-288. DOI:https://doi.org/10.1145/2069618.2069665

[35] Stefanie Mueller. 2017. 3D Printing for Human-computer Interaction. interactions 24, 5 (August 2017), 76-79. DOI:https://doi.org/10.1145/3125399

[36] Stefanie Mueller, Anna Seufert, Huaishu Peng, Robert Kovacs, Kevin Reuss, François Guimbretière, and Patrick Baudisch. 2019. FormFab: Continuous Interactive Fabrication. In Proceedings of the Thirteenth International Conference on Tangible, Embedded, and Embodied Interaction (TEI '19), ACM, New York, NY, USA, 315-323. DOI:https://doi.org/10.1145/3294109.3295620

[37] Beth Nam, Alex Berman, Brittany Garcia, and Sharon Chu. 2019. Towards the Meaningful 3D-Printed Object: Understanding the Materiality of 3D Prints. In Design, User Experience, and Usability. Practice and Case Studies (Lecture Notes in Computer Science), Springer International Publishing, Cham, 533-552. DOI:https: //doi.org/10.1007/978-3-030-23535-2_39

[38] William Oropallo and Les A. Piegl. 2016. Ten challenges in 3D printing. Engineering with Computers 32, 1 (2016), 135-148.

[39] Julian E. Orr. 1996. Talking about machines: An ethnography of a modern job. Cornell University Press.

[40] Neri Oxman, Christine Ortiz, Fabio Gramazio, and Matthias Kohler. 2015. Material ecology. Computer-Aided Design 60 (March 2015), 1-2.

[41] Nadya Peek and Stephanie Mueller. 2019. Making Machines That Make. IEEE Pervasive Computing 18, 1 (2019), 84-88.

[42] Huaishu Peng, Jimmy Briggs, Cheng-Yao Wang, Kevin Guo, Joseph Kider, Stefanie Mueller, Patrick Baudisch, and François Guimbretière. 2018. RoMA: Interactive Fabrication with Augmented Reality and a Robotic 3D Printer. In Proceedings of the 2018 CHI Conference on Human Factors in Computing Systems (CHI '18), ACM, New York, NY, USA, 579:1-579:12. DOI:https://doi.org/10.1145/3173574.3174153

[43] Thiago Pereira, Szymon Rusinkiewicz, and Wojciech Matusik. 2014. Computational Light Routing: 3D Printed Optical Fibers for Sensing and Display. ACM Trans. Graph.33, 3 (June 2014), 24:1-24:13. DOI:https://doi.org/10.1145/2602140

[44] Andrew Pickering. 1995. The Mangle of Practice: Time, Agency, and Science.University of Chicago Press, Chicago.

[45] Matt Ratto and Robert Ree. 2012. Materializing information: 3D printing and social change. First Monday 17, 7 (2012). Retrieved from http://firstmonday.org/ ojs/index.php/fm/article/view/3968/3273\&gt

[46] Erica Robles and Mikael Wiberg. 2010. Texturing the "Material Turn" in Interaction Design. In Proceedings of the Fourth International Conference on Tangible, Embedded, and Embodied Interaction (TEI '10), ACM, New York, NY, USA, 137-144. DOI:https://doi.org/10.1145/1709886.1709911

[47] Jeremy Rose and Matthew Jones. 2005. The double dance of agency: a sociotheoretic account of how machines and humans interact. Systems, Signs \& Actions 1, 1 (2005), 19-37.

[48] Valkyrie Savage, Sean Follmer, Jingyi Li, and Björn Hartmann. 2015. Makers' Marks: Physical Markup for Designing and Fabricating Functional Objects. In Proceedings of the 28th Annual ACM Symposium on User Interface Software \& Technology (UIST '15), ACM, New York, NY, USA, 103-108. DOI:https://doi.org/
$10.1145 / 2807442.2807508$

[49] Martin Schmitz, Martin Herbers, Niloofar Dezfuli, Sebastian Günther, and Max Mühlhäuser. 2018. Off-Line Sensing: Memorizing Interactions in Passive 3DPrinted Objects. In Proceedings of the 2018 CHI Conference on Human Factors in Computing Systems (CHI '18), ACM, New York, NY, USA, 182:1-182:8. DOI:https: //doi.org/10.1145/3173574.3173756

[50] Ryoung Seo-Zindy and Richard Heeks. 2017. Researching the Emergence of 3D Printing, Makerspaces, Hackerspaces and FabLabs in the Global South: A Scoping Review and Research Agenda on Digital Innovation and Fabrication Networks. The Electronic fournal of Information Systems in Developing Countries 80, 1 (2017), 1-24. DOI:https://doi.org/10.1002/j.1681-4835.2017.tb00589.x

[51] Kimberly Sheridan, Erica Rosenfeld Halverson, Breanne Litts, Lisa Brahms, Lynette Jacobs-Priebe, and Trevor Owens. 2014. Learning in the making: A comparative case study of three makerspaces. Harvard Educational Review 84, 4 (2014), 505-531.

[52] Rita Shewbridge, Amy Hurst, and Shaun K. Kane. 2014. Everyday Making: Identifying Future Uses for 3D Printing in the Home. In Proceedings of the 2014 Conference on Designing Interactive Systems (DIS '14), ACM, New York, NY, USA, 815-824. DOI:https://doi.org/10.1145/2598510.2598544

[53] Johan Söderberg. 2019. The cloud factory: Making things and making a living with desktop 3D printing. Culture and Organization 25, 1 (January 2019), 65-81. DOI:https://doi.org/10.1080/14759551.2016.1203313

[54] Oliver Stickel, Konstantin Aal, Verena Fuchsberger, S Rüller, V. Wenzelmann, V. Pipek, V. Wulf, and M. Tscheligi. 2017. 3D printing/digital fabrication for education and the common good: Workshop at the International Conference on Communities \& Technologies 2017. In Proceedings of the 8th International Conference on Communities and Technologies, ACM, 315-318. Retrieved from http://dl.acm.org/citation.cfm?id=3083708

[55] Lucy Suchman. 2007. Human-machine reconfigurations: Plans and situated actions. Cambridge University Press.

[56] Anna Vallgårda and Tomas Sokoler. 2009. A Material Focus: Exploring Properties of Computational Composites. In CHI '09 Extended Abstracts on Human Factors in Computing Systems (CHI EA '09), ACM, New York, NY, USA, 4147-4152. DOI:https://doi.org/10.1145/1520340.1520631

[57] Kiril Vidimce, Alexandre Kaspar, Ye Wang, and Wojciech Matusik. 2016. Foundry: Hierarchical Material Design for Multi-Material Fabrication. In Proceedings of the 29th Annual Symposium on User Interface Software and Technology (UIST '16), ACM, New York, NY, USA, 563-574. DOI:https://doi.org/10.1145/2984511.2984516

[58] Ron Wakkary, William Odom, Sabrina Hauser, Garnet Hertz, and Henry Lin. 2015. Material Speculation: Actual Artifacts for Critical Inquiry. In Proceedings of The Fifth Decennial Aarhus Conference on Critical Alternatives (CA '15), Aarhus University Press, 97-108. DOI:https://doi.org/10.7146/aahcc.v1i1.21299

[59] Mikael Wiberg. 2014. Methodology for Materiality: Interaction Design Research Through a Material Lens. Personal Ubiquitous Comput.18, 3 (March 2014), 625-636. DOI.https://doi.org/10.1007/s00779-013-0686-7

[60] Mikael Wiberg. 2018. The materiality of interaction: notes on the materials of interaction design. MIT Press. Retrieved September 19, 2019 from http://urn.kb. se/resolve?urn=urn:nbn:se:umu:diva- 147261

[61] Amanda Williams and Bruno Nadeau. 2014. Manufacturing for Makers: From Prototype to Product. interactions 21, 6 (October 2014), 64-67. DOI:https://doi. org $/ 10.1145 / 2674964$

[62] Longyu Zhang, Haiwei Dong, and Abdulmotaleb El Saddik. 2015. From 3D Sensing to Printing: A Survey. ACM Trans. Multimedia Comput. Commun. Appl.12, 2 (October 2015), 27:1-27:23. DOI:https://doi.org/10.1145/2818710 